\title{
Acúmulo de massa seca e nutrientes pelo tomateiro 'SM-16' cultivado em solo com diferentes coberturas
}

\author{
Rafaella Rayane M de Lucena; Maria Zuleide de Negreiros; José Francismar de Medeiros; Thaíza \\ Mabelle de V Batista; Antonia Tamires M Bessa; Welder de AR Lopes \\ UFERSA - Depto. Ciências Vegetais, C. Postal 137, 59625-900 Mossoró-RN; rafaellarayane@hotmail.com; zuleide@ufersa.edu.br; \\ jfmedeir@ufersa.edu.br; thaizamabelle@hotmail.com; tami.bessa@hotmail.com; welder.lopes@hotmail.com
}

\begin{abstract}
RESUMO
Com o objetivo de avaliar o acúmulo de massa seca e nutrientes pelo tomateiro 'SM-16' em solo com diferentes coberturas conduziu-se um experimento na WG Fruticultura, Baraúna-RN, entre setembro/2009 e janeiro/2010. Foram estudados os tipos de cobertura do solo: 1) solo descoberto; 2) filme de polietileno preto, 3) filme de polietileno branco, 4) filme de polietileno cinza e 5) polipropileno preto (TNT). Os tratamentos foram dispostos em parcelas subdivididas, sendo as parcelas representadas pelas coberturas e as subparcelas pelas épocas de amostragens das plantas: 14, 28, 42, 56, 70, 84, 98 e 112 dias após o transplantio. O delineamento experimental adotado foi de blocos casualizados completos, com quatro repetições. As coberturas do solo não influenciaram o acúmulo de massa seca do tomateiro. Os frutos foram os drenos preferenciais da planta, chegando ao final do ciclo com $48,6 \%$ do total da massa seca acumulada. Apenas o acúmulo de $\mathrm{N}, \mathrm{Ca}$ e Mg nos frutos e de $\mathrm{K}$ nas folhas foram influenciados pelas coberturas do solo. As maiores médias foram obtidas utilizando-se o polietileno branco, resultando em 137,73 e 8,84 kg/ha de acúmulo de $\mathrm{N}$ e $\mathrm{Mg}$ nos frutos, respectivamente. O uso do TNT resultou em acúmulo de 4,02 e 134,23 kg/ha respectivamente de Ca nos frutos e de $\mathrm{K}$ nas folhas. $\mathrm{O}$ acúmulo de nutrientes em ordem decrescente na planta foi: $\mathrm{K}>\mathrm{N}>\mathrm{Ca}>\mathrm{Mg}>\mathrm{P}$, sendo $\mathrm{N}, \mathrm{P}$ e $\mathrm{K}$ encontrados em maiores quantidades nos frutos, e $\mathrm{Ca}$ e $\mathrm{Mg}$ nas folhas.
\end{abstract}

Palavras-chave: Lycopersicon esculentum, mulching, fitomassa, marcha de absorção de macronutrientes.

\begin{abstract}
Dry mass and nutrients accumulation by tomato 'SM-16' cultivated in different mulching

The dry mass and nutrients accumulation by tomato 'SM-16' cultivated in different mulching was carried out on an experiment in WG Fruticultura, Baraúna, Rio Grande do Norte state, Brazil, from September 2009 to January 2010. The treatments consisted of 1) uncovered soil, 2) black polyethylene film, 3) white polyethylene film, 4) gray polyethylene film and 5) black polypropylene (TNT). Treatments were arranged in split plots with the plots represented by mulching and split plots by the time of sampling the plants: 14,28 , $42,56,70,84,98$ and 112 days after transplanting. The experimental design utilized was a randomized complete block with four replications. Mulching did not affect the dry mass accumulation of the plants. The fruits behaved as preferential sink of the plant, reaching the end of the cycle with $48.6 \%$ of the total accumulated dry mass. Only N, Ca and $\mathrm{Mg}$ accumulation in the fruits and $\mathrm{K}$ accumulation in the leaves were influenced by mulching. Using white polyethylene resulted in the highest averages, respectively in the accumulation of 137.73 and $8.84 \mathrm{~kg} / \mathrm{ha}$ of $\mathrm{N}$ and $\mathrm{Mg}$ on fruits. Using TNT resulted in the accumulation of 4.02 and $134.23 \mathrm{~kg} / \mathrm{ha}$ of $\mathrm{Ca}$ and $\mathrm{K}$ on fruits and leaves, respectively. The nutrients accumulation in the plants in decreasing order were $\mathrm{K}>\mathrm{N}>\mathrm{Ca}>\mathrm{Mg}>\mathrm{P} ; \mathrm{N}, \mathrm{P}$ and $\mathrm{K}$ being found in higher quantities in fruits, and $\mathrm{Ca}$ and $\mathrm{Mg}$ in leaves.
\end{abstract}

Keywords: Lycopersicon esculentum, mulching, phytomass, absorption march of macronutrients.

(Recebido para publicação em 17 de maio de 2012; aceito em 8 de julho de 2013)

(Received on May 17, 2012; accepted on July 8, 2013)

\begin{abstract}
$\mathrm{A}$ maioria dos produtores de tomate do Rio Grande do Norte tem utilizado cultivares de dupla aptidão, que são os industriais comercializados para consumo in natura. Isso tem ocorrido em virtude do menor custo de produção em relação às cultivares do Grupo Santa Cruz ou Salada, uma vez que esse tipo de tomate apresenta crescimento determinado, ou seja, pára seu desenvolvimento depois da floração, e dispensa práticas como o tutoramento e a desbrota, além de apresentar ciclo mais curto (Alvarenga, 2004).
\end{abstract}

A busca por melhor ambiente para o cultivo do tomate tipo Santa Cruz tem sido o foco principal no Rio Grande do Norte, havendo a necessidade de pesquisas com a cultura no que diz respeito ao seu manejo, que inclui o estudo de tratos culturais como o uso de cobertura do solo. Essa prática, por sua vez, tornou-se importante e bastante difundida na produção de diversas espécies de hortaliças, constituindo-se, inclusive, em condição básica para que muitas delas apresentem produtos com qualidade aceitável, em níveis rentáveis de produtividade.
A utilização de cobertura do solo proporciona maior conservação de água e nutrientes do solo, aumento da atividade microbiana, efeito repelente sobre insetos, maior controle sobre plantas invasoras e proteção do fruto do contato direto com o solo (Sampaio \& Araújo, 2001; Câmara et al., 2007). No Pólo Agrícola RN/CE, os filmes plásticos prateado e branco são bastante utilizados pelos produtores de melão e melancia, embora alguns desses, por questões econômicas, utilizem ainda o plástico preto. 
Com o uso de novas técnicas de cultivo e de materiais genéticos, bem como, os ganhos nos conhecimentos existentes sobre o processo produtivo do tomateiro, tem sido importante o estudo do crescimento e da curva de absorção de nutrientes pela cultura conduzida segundo as práticas culturais vigentes. As curvas de absorção, até então existentes na literatura nacional, foram obtidas em áreas com produtividades próximas da metade das atualmente encontradas pelos agricultores que utilizam novas tecnologias, dentre essas, a cobertura do solo (Anti, 2004).

Em tomateiro 'Duradoro', sob cultivo protegido, aos 45 dias após o transplantio, o crescimento vegetativo, representado pelas médias de altura de plantas, nas parcelas com cobertura do solo com filme plástico preto foi maior que o obtido nas parcelas com solo descoberto, sem diferir, entretanto, daquele nas parcelas cobertas com filme plástico branco (Bogiani et al., 2008).

Do ponto de vista agronômico, a análise de crescimento, expresso pela acumulação de massa seca, e o acúmulo de nutrientes podem ser úteis no estudo do comportamento vegetal sob diferentes condições ambientais. Permite também avaliar o crescimento final da planta como um todo e a contribuição dos diferentes órgãos no crescimento, além de auxiliar nas adubações, pela quantificação do acúmulo de nutrientes (Feltrim et al., 2008).

Em tomate híbrido 'Thomas', observou-se que o acúmulo de macronutrientes na parte aérea, em ordem decrescente de quantidade, foi: $\mathrm{K}>\mathrm{N}>\mathrm{Ca}>\mathrm{S}>\mathrm{Mg}>\mathrm{P}$. Verificou-se ainda, que as maiores quantidades de $\mathrm{N}, \mathrm{P}$ e $\mathrm{K}$ foram encontradas no fruto, estando $\mathrm{Ca}, \mathrm{Mg}$ e $\mathrm{S}$ em maiores concentrações nas partes vegetativas (Villas Bôas, 2002).

O presente trabalho teve como objetivo obter informações relativas ao acúmulo de massa seca e nutrientes pelo tomateiro 'SM-16' cultivado em solo com diferentes coberturas.

\section{MATERIAL E MÉTODOS}

O experimento foi instalado na WG Fruticultura, no município de
Baraúna-RN ( $5^{\circ} 05^{\prime} \mathrm{S}, 37^{\circ} 38^{\prime} \mathrm{O}, 95 \mathrm{~m}$ de altitude.), entre setembro/2009 e janeiro/2010.

O solo da área experimental é classificado como Cambissolo Háplico (Embrapa, 1999), cujos resultados médios das análises químicas, foram $\mathrm{pH}$ $\left(\mathrm{H}_{2} \mathrm{O}\right)=7,5 ; \mathrm{Ca}=6,3 \mathrm{cmol}_{\mathrm{c}} / \mathrm{dm}^{3} ; \mathrm{Mg}=$ $1,8 \mathrm{cmol} / \mathrm{dm}^{3} ; \mathrm{K}=0,29 \mathrm{cmol} / \mathrm{dm}^{3} ; \mathrm{Al}=$ $0,00 \mathrm{cmol}_{\mathrm{c}} / \mathrm{dm}^{3} ; \mathrm{P}=47,8 \mathrm{mg} / \mathrm{dm}^{3}$.

Foram estudados os tipos de cobertura do solo: 1) solo descoberto [testemunha (SC)], 2) filmes de polietileno preto (PR), 3) filmes de polietileno branco [dupla face preto e branco (BR)] e 4) filmes de polietileno cinza [dupla face preto e cinza (CI)] e 5) polipropileno preto (agrotêxtil ou TNT). Os tratamentos foram dispostos em parcelas subdivididas, sendo as parcelas representadas pelas coberturas e as subparcelas pelas épocas de amostragens das plantas [14, 28, 42, 56, 70, 84, 98 e 112 dias após o transplantio (DAT)]. O delineamento experimental adotado foi de blocos casualizados completos, com quatro repetições. Cada bloco, com $20 \mathrm{~m}$ de comprimento e $30 \mathrm{~m}$ de largura, foi constituído por quinze fileiras de plantas, sendo a parcela composta por três fileiras de plantas, com espaçamento de 2,0 $\mathrm{m}$ entre fileiras e $0,50 \mathrm{~m}$ entre plantas, com área total e útil de 84 e 26 $\mathrm{m}^{2}$, respectivamente.

A semeadura foi realizada em bandejas de poliestireno expandido de 200 células, utilizando-se o substrato comercial Golden Mix $^{\circledR}$. As mudas foram transplantadas em 26 de setembro/2009, no estádio de quatro a seis folhas definitivas, 25 dias após a semeadura.

O preparo do solo constou de uma aração e duas gradagens, seguido do sulcamento em linhas, com profundidade de $20 \mathrm{~cm}$, onde foi realizada a adubação de plantio com $400 \mathrm{~kg} / \mathrm{ha}$ de monoamônio fosfato (MAP), com posterior fechamento dos sulcos. O sistema de irrigação utilizado foi gotejamento, com fita flexível de $16 \mathrm{~mm}$ e gotejadores com vazão de $1,5 \mathrm{~L} / \mathrm{h}$, à pressão de 100 $\mathrm{KPa}$. A quantidade de água de irrigação variou de acordo com a evapotranspiração da cultura (ETc), estimada pela metodologia do Kc dual segundo Allen et al. (2006), considerando os Kc para a fase inicial de 0,60; para a fase inter- mediária, de 1,05 e para a fase final do ciclo, de 0,80 .

Após a instalação do sistema de irrigação, as coberturas plásticas e o TNT preto foram colocados sobre os camalhões, correspondentes às fileiras de plantas, nas parcelas dos tratamentos com cobertura do solo. Os filmes de polietileno preto, cinza e branco tinham 0,25 micras de espessura, e o agrotêxtil preto apresentava $45 \mathrm{~g} / \mathrm{m}^{2}$ de gramatura, sendo a superfície coberta de $80 \mathrm{~cm}$ de largura. Posteriormente, efetuou-se a abertura dos orifícios de plantio, distanciados $0,50 \mathrm{~m}$, com um vazador de 60 $\mathrm{mm}$ de diâmetro.

As adubações em cobertura foram efetuadas diariamente via fertirrigação, de acordo com a análise de solo, e obedecendo aos estádios de desenvolvimento da cultura; para tanto, utilizaram-se $225 \mathrm{~kg} / \mathrm{ha}$ de $\mathrm{N}, 125 \mathrm{~kg} / \mathrm{ha}$ de $\mathrm{P}_{2} \mathrm{O}_{5}$ e 390 $\mathrm{kg} /$ ha de $\mathrm{K}_{2} \mathrm{O}$. As fontes de nitrogênio utilizadas foram uréia $(63,38 \%)$, MAP $(12,92 \%)$, nitrato de cálcio $(18,14 \%)$ e ácido nítrico (3,56\%). Para o $\mathrm{P}_{2} \mathrm{O}_{5}$ e $\mathrm{K}_{2} \mathrm{O}$, as fontes utilizadas foram $100 \%$ de MAP e $100 \%$ cloreto de potássio, respectivamente.

Para quantificar o acúmulo de massa seca e nutrientes foram amostradas plantas de tomate em intervalos de quatorze dias, dos 14 até os 112 DAT. Na primeira coleta, obteve-se duas plantas competitivas, aleatoriamente, por parcela, e nas demais apenas uma. As folhas e/ou frutos que caiam no final do ciclo, em virtude da senescência da planta, não foram utilizadas na amostragem. Após cada coleta, as plantas foram fracionadas em caules, folhas, inflorescências e frutos, lavadas e colocadas em estufa com circulação de ar à temperatura de $65^{\circ} \mathrm{C}$ até atingir massa constante. As amostras foram trituradas em moinho tipo Willey (peneira de $2 \mathrm{~mm}$ ) e acondicionadas em recipientes fechados.

Para determinação dos teores de N, $\mathrm{P}, \mathrm{K}, \mathrm{Ca}$ e $\mathrm{Mg}$, foram pesadas amostras de $0,4 \mathrm{~g}$, e em seguida, foi feita a extração com peróxido de hidrogênio (2 $\mathrm{mL})$, ácido sulfúrico concentrado $(4 \mathrm{~mL})$ e mistura digestora $(0,7 \mathrm{~g})$, composta de sulfato de sódio, sulfato de cobre e selênio (metálico). Os teores de $\mathrm{N}$ foram determinados pelo método Micro-Kjeldahl, através do destilador de N; de 
P por colorimetria, utilizando o método do complexo fosfo-molíbdico em meio redutor, adaptado por Braga \& Defelipo (1974); de K por fotometria de emissão de chama; e de Ca e Mg por absorção atômica (Embrapa, 1999). Em função dos teores de massa seca das amostras, foi determinado o acúmulo de massa seca, e o acúmulo de macronutrientes em cada época de coleta, sendo os resultados em kg/ha.

Os dados foram submetidos às análises de variância, ao nível de 5\%, usando o software SISVAR v5.3 (Ferreira, 2007) e de regressões não-lineares utilizando-se o software Table Curve 2D v2.00 (Jandel Scientific, 1991).

\section{RESULTADOS E DISCUSSÃO}

A análise estatística dos resultados obtidos para o acúmulo de massa seca nas folhas (MFO), caules (MCA), inflorescências (MFL) e frutos (MFR) pelo tomateiro 'SM-16' indicou haver diferenças significativas apenas com relação às épocas de amostragem de plantas (DAT).

O crescimento da planta, expresso pelo acúmulo de massa seca ao longo do ciclo, foi lento até os 28 DAT (Figura 1A) independentemente dos tipos de coberturas do solo. Esse crescimento inicial lento foi resultado de as plantas gastarem grande parte da energia para fixação no solo, uma vez que nessa fase as raízes são o dreno preferencial dos fotoassimilados (Pace et al., 1999). Gargantini \& Blanco (1963), utilizando o tomate Santa Cruz verificaram que o crescimento inicial também foi lento, intensificando-se a partir dos quarenta dias após a germinação.

A partir dos 28 DAT, o crescimento foi significativamente mais acelerado, atingindo aos 94 DAT a produção máxima estimada de massa seca total de 7,67 t/ha(Figura 1A). Observou-se que com o início do processo reprodutivo, os carboidratos e outros compostos foram translocados das folhas para os frutos, como decorrência da predominância da fase reprodutiva sobre a vegetativa (Marschner, 2012). Dessa forma, as folhas, os caules, as inflorescências e os frutos apresentaram valores máximos estimados de massa seca de 2.613,22,
$1.293,84,298,85$ e $3.861,38 \mathrm{~kg} / \mathrm{ha}$, aos $85,92,93$ e 98 DAT, respectivamente (Figura 1A).

O fato de as coberturas do solo não terem influenciado o crescimento do tomateiro 'SM-16' pode estar relacionado com as mudanças microclimáticas. A taxa de transpiração da planta e a temperatura são fortemente associadas com o microclima, assim, dados micro-meteorológicos podem contribuir para a alteração dos mecanismos fisiológicos.

Por outro lado, Lopes et al. (2011), trabalhando também com o tomateiro 'SM-16' e com coberturas de solo semelhantes, constataram que elas influenciaram o acúmulo de massa seca nas folhas, ramos e frutos, sendo o TNT a que promoveu as maiores médias. Isso implica que diferenças ambientais associadas às genotípicas podem explicar as diferenças observadas entre esses resultados.

A distribuição de assimilados nos diferentes órgãos das plantas de tomate 'SM-16' seguiu o mesmo padrão para todas as coberturas do solo. No início do ciclo, aos 14 DAT, as folhas se comportaram como fonte-dreno, uma vez que foram responsáveis pela produção de fotoassimilados, e também o órgão com maior armazenamento, acumulando $79,0 \%$ da massa seca total da planta. Nessa mesma época, os caules foram drenos fortes, mantendo-se dessa forma até o final do ciclo. A partir dos 28 DAT, com o início da fase reprodutiva e emissão das primeiras inflorescências, já foi possível perceber deslocamento dos assimilados das folhas, que nessa época representavam $74,6 \%$ da massa seca total, para os caules $(24,4 \%)$ e inflorescências $(1,0 \%)$. Com o início da frutificação, aos 42 DAT, o direcionamento dos assimilados das folhas para os frutos ocorreu de forma intensa, acumulando ao final do ciclo, 48,6\% da massa seca total. O maior acúmulo de massa seca em favor dos frutos comprova que os mesmos comportaram-se como dreno principal da planta (Figura 1B).

Comportamentos semelhantes foram

Tabela 1. N, Ca e Mg nos frutos do tomateiro 'SM-16' em diferentes coberturas do solo ( $\mathrm{N}, \mathrm{Ca}$ and $\mathrm{Mg}$ in fruits of tomato 'SM-16', cultivated under different mulching). Baraúna, UFERSA, 2010.

\begin{tabular}{|c|c|c|c|c|c|c|}
\hline \multirow{3}{*}{ Coberturas } & \multicolumn{6}{|c|}{ N nos frutos (kg/ha) } \\
\hline & 42 & 56 & 70 & 84 & 98 & 112 \\
\hline & \multicolumn{6}{|c|}{ (DAT) } \\
\hline Sem cobertura & $0,45 \mathrm{a}$ & $10,33 a$ & $43,05 a$ & $77,15 \mathrm{a}$ & $92,65 b$ & $67,67 a$ \\
\hline Poliet. branco & $1,00 \mathrm{a}$ & $14,97 \mathrm{a}$ & $32,31 \mathrm{a}$ & $73,04 \mathrm{a}$ & $137,73 a$ & $79,65 a$ \\
\hline Poliet. cinza & $0,58 \mathrm{a}$ & $6,68 \mathrm{a}$ & $40,07 \mathrm{a}$ & $73,08 \mathrm{a}$ & $78,24 b$ & $85,65 a$ \\
\hline Poliet. preto & $0,28 \mathrm{a}$ & $5,72 \mathrm{a}$ & $36,37 \mathrm{a}$ & $72,39 a$ & $69,33 b$ & $64,12 \mathrm{a}$ \\
\hline \multirow[t]{2}{*}{ TNT } & - & $5,88 \mathrm{a}$ & $42,16 \mathrm{a}$ & $68,08 \mathrm{a}$ & $125,04 \mathrm{a}$ & $86,64 a$ \\
\hline & \multicolumn{6}{|c|}{ Ca nos frutos (kg/ha) } \\
\hline Sem cobertura & $0,02 \mathrm{a}$ & $0,40 \mathrm{a}$ & $1,56 \mathrm{a}$ & $2,25 \mathrm{a}$ & $1,85 b$ & $1,91 \mathrm{c}$ \\
\hline Poliet. branco & $0,05 \mathrm{a}$ & $0,73 a$ & $1,71 \mathrm{a}$ & $1,70 \mathrm{ab}$ & $3,27 \mathrm{a}$ & $3,16 \mathrm{ab}$ \\
\hline Poliet. cinza & $0,02 \mathrm{a}$ & $0,39 \mathrm{a}$ & $1,88 \mathrm{a}$ & $1,03 b$ & $1,46 b$ & $3,42 \mathrm{a}$ \\
\hline Poliet. preto & $0,01 \mathrm{a}$ & $0,34 \mathrm{a}$ & $2,11 \mathrm{a}$ & $1,53 \mathrm{ab}$ & $0,94 b$ & $2,03 \mathrm{bc}$ \\
\hline \multirow[t]{2}{*}{ TNT } & - & $0,41 \mathrm{a}$ & $1,81 \mathrm{a}$ & $1,02 \mathrm{~b}$ & $4,02 \mathrm{a}$ & $2,78 \mathrm{abc}$ \\
\hline & \multicolumn{6}{|c|}{ Mg nos frutos (kg/ha) } \\
\hline Sem cobertura & $0,03 \mathrm{a}$ & $0,65 \mathrm{a}$ & $2,26 a$ & $4,66 \mathrm{a}$ & $5,78 b$ & $4,59 \mathrm{c}$ \\
\hline Poliet. branco & $0,06 \mathrm{a}$ & $0,87 \mathrm{a}$ & $1,96 a$ & $5,07 \mathrm{a}$ & $8,84 \mathrm{a}$ & $5,44 \mathrm{abc}$ \\
\hline Poliet. cinza & $0,03 \mathrm{a}$ & $0,45 \mathrm{a}$ & $2,29 \mathrm{a}$ & $4,39 a$ & $5,22 b$ & $6,20 \mathrm{ab}$ \\
\hline Poliet. preto & $0,01 \mathrm{a}$ & $0,42 \mathrm{a}$ & $2,14 \mathrm{a}$ & $4,75 \mathrm{a}$ & $4,40 \mathrm{~b}$ & $4,80 \mathrm{bc}$ \\
\hline TNT & - & $0,43 a$ & $2,16 \mathrm{a}$ & $4,48 \mathrm{a}$ & $8,34 \mathrm{a}$ & $6,74 a$ \\
\hline
\end{tabular}

Médias seguidas da mesma letra nas colunas não diferem entre si pelo teste de Tukey a 5\% de probabilidade (means followed by the same letter in columns do not differ by Tukey test, at $5 \%$ probability). 
observados por Fayad et al. (2001), que também verificaram que os frutos foram o dreno preferencial da planta, tanto para o tomate EF-50 como para a cv. Santa Clara, sendo esses órgãos responsáveis por 68 e $51 \%$ do total da massa seca produzida pela planta, respectivamente. Lopes et al. (2011) verificaram que os frutos do tomateiro representaram, ao final do ciclo, $52,5 \%$ do total da massa seca acumulada, enquanto as folhas acumularam $28,5 \%$, os ramos $14,8 \%$, e os cachos florais $4,3 \%$.

Há a hipótese de que a distribuição da massa seca na planta seja regulada pela força do dreno dos órgãos, termo usado para descrever a habilidade competitiva de um órgão atrair assimilados, quantificada pelas suas taxas de crescimentos potenciais (Heuvelink, 1996; Grangeiro et al., 2005).

Quanto ao acúmulo de nutrientes pelo tomateiro, houve efeito significativo da interação coberturas do solo (mulching) e épocas de amostragem de plantas para acúmulo de nitrogênio nos frutos (NFR), acúmulo de potássio nas folhas (KFO), acúmulo de cálcio nos frutos (CaFR) e acúmulo de magnésio nos frutos (MgFR).
O nitrogênio (N) foi o segundo nutriente mais acumulado pelo tomateiro. Assim como observado na massa seca total da parte aérea das plantas, o acúmulo de $\mathrm{N}$ foi lento durante os primeiros 28 DAT. A partir dessa idade observou-se um incremento significativo, atingindo o máximo estimado de $183,36 \mathrm{~kg} / \mathrm{ha}$, aos 93 DAT (Figura 2A). Segundo Sengik (2010), esse nutriente tem maior e mais rápido efeito sobre o crescimento vegetal; daí, a semelhança entre as curvas; além disso, promove o desenvolvimento do sistema radicular e melhora a absorção de outros nu-

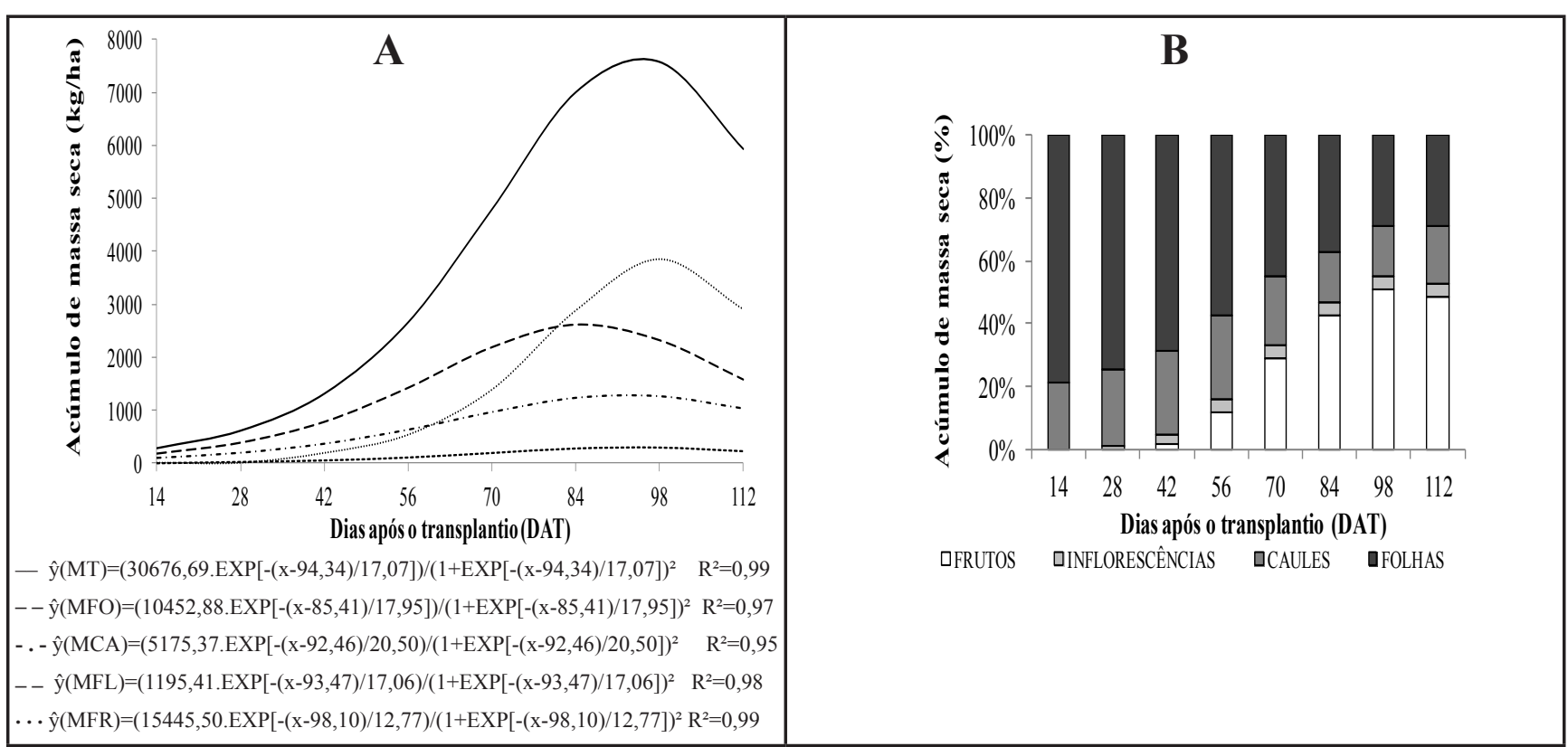

Figura 1. Acúmulo de massa seca total (MT), nas folhas (MFO), nos caules (MCA), nas inflorescências (MFL) e nos frutos (MFR) (A) e partição de assimilados (B) pelo tomateiro 'SM-16' em diferentes coberturas do solo, em função dos dias após o transplantio (DAT) (dry matter accumulation (MT), in leaves (MFO), stem (MCA), inflorescences (MFL) and fruits (MFR) (A) and assimilate partitioning (B) by tomato 'SM-16' in different mulching depending on days after transplanting (DAT)). Baraúna, UFERSA, 2010.

Tabela 2. K nas folhas do tomateiro 'SM-16' em diferentes coberturas do solo ( $\mathrm{K}$ in leaves of tomato 'SM-16', cultivated under different mulching). Baraúna, UFERSA, 2010.

\begin{tabular}{lcccccccc}
\hline \multirow{2}{*}{ Coberturas } & \multicolumn{7}{c}{ K nas folhas (kg/ha) } \\
\cline { 2 - 8 } & $\mathbf{1 4}$ & $\mathbf{2 8}$ & $\mathbf{4 2}$ & $\mathbf{5 6}$ & $\mathbf{7 0}$ & $\mathbf{8 4}$ & $\mathbf{9 8}$ & $\mathbf{1 1 2}$ \\
\cline { 2 - 8 } & & & \multicolumn{7}{c}{ (DAT) } \\
\hline Sem cobertura & $0,26 \mathrm{a}$ & $5,25 \mathrm{a}$ & $26,68 \mathrm{a}$ & $58,52 \mathrm{ab}$ & $92,70 \mathrm{a}$ & $93,34 \mathrm{~b}$ & $53,89 \mathrm{a}$ & $30,71 \mathrm{a}$ \\
Poliet. branco & $0,59 \mathrm{a}$ & $9,06 \mathrm{a}$ & $38,11 \mathrm{a}$ & $52,87 \mathrm{ab}$ & $105,12 \mathrm{a}$ & $74,10 \mathrm{bc}$ & $45,34 \mathrm{a}$ & $36,36 \mathrm{a}$ \\
Poliet. cinza & $0,38 \mathrm{a}$ & $5,05 \mathrm{a}$ & $20,49 \mathrm{a}$ & $60,31 \mathrm{ab}$ & $83,48 \mathrm{a}$ & $87,20 \mathrm{~b}$ & $39,56 \mathrm{a}$ & $40,12 \mathrm{a}$ \\
Poliet. preto & $0,32 \mathrm{a}$ & $5,29 \mathrm{a}$ & $19,10 \mathrm{a}$ & $43,71 \mathrm{~b}$ & $85,88 \mathrm{a}$ & $57,69 \mathrm{c}$ & $42,43 \mathrm{a}$ & $26,86 \mathrm{a}$ \\
TNT & $0,39 \mathrm{a}$ & $6,57 \mathrm{a}$ & $31,75 \mathrm{a}$ & $69,03 \mathrm{a}$ & $95,40 \mathrm{a}$ & $134,23 \mathrm{a}$ & $43,37 \mathrm{a}$ & $48,45 \mathrm{a}$ \\
\hline
\end{tabular}

Médias seguidas da mesma letra nas colunas não diferem entre si pelo teste de Tukey a $5 \%$ de probabilidade (means followed by the same letter in columns do not differ by Tukey test at $5 \%$ probability). 


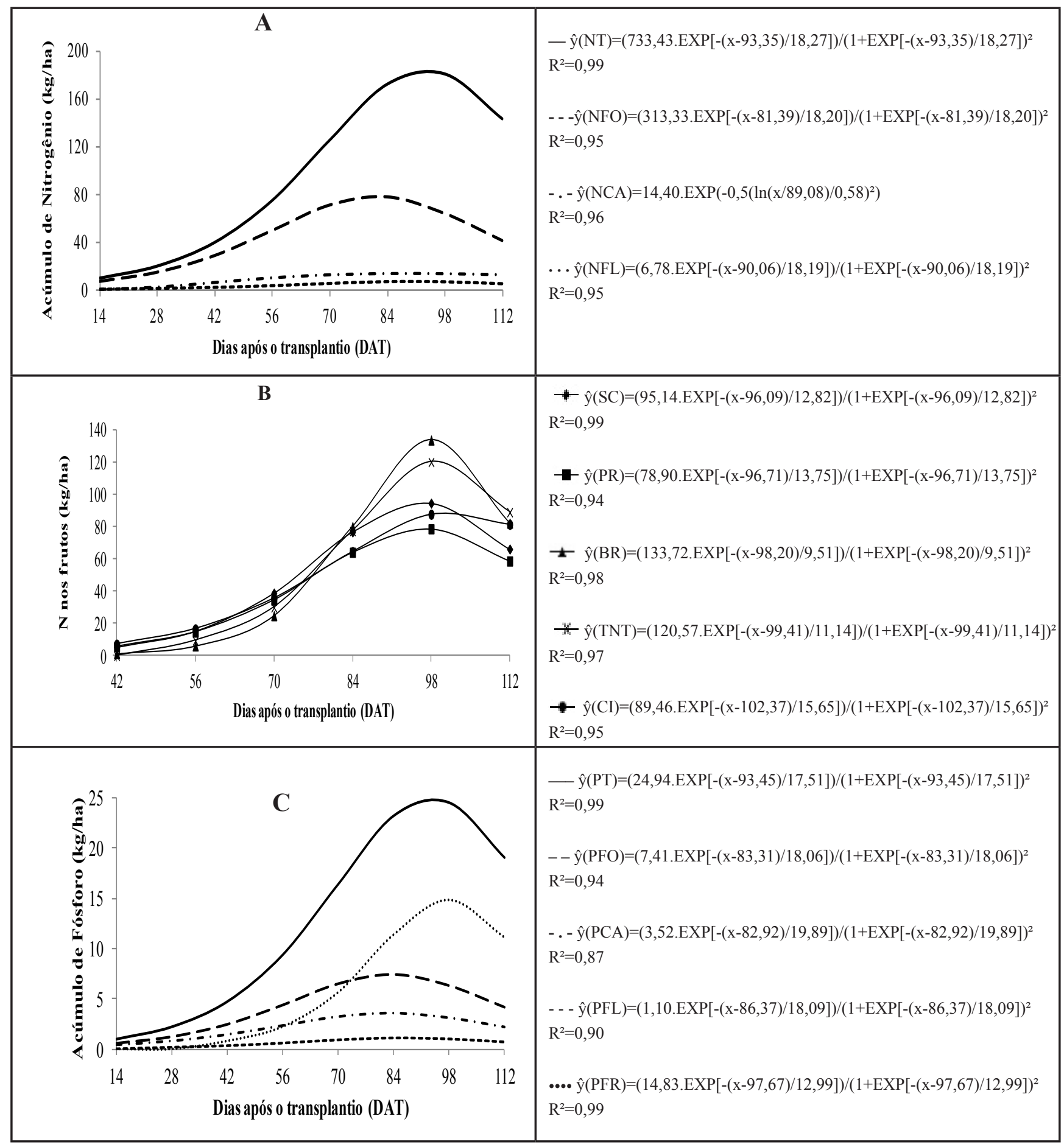

Figura 2. Acúmulo de nitrogênio total (NT), nas folhas (NFO), nos caules (NCA), nas inflorescências (NFL) (A) e nos frutos (NFR) (B), e acúmulo de fósforo total (PT), nas folhas (PFO), nos caules (PCA), nas inflorescências (PFL) e nos frutos (PFR) (C) pelo tomateiro 'SM-16' em diferentes coberturas do solo, em função dos dias após o transplantio (DAT) [total nitrogen accumulation (NT), in leaves (NFO), stem (NCA), inflorescences (NFL) (A) and fruits (NFR) (B), and total phosphorus accumulation (PT), in leaves (PFO), stem (PCA), inflorescences (PFL) and fruits (PFR) (C) by tomato 'SM-16' in different mulching depending on days after transplanting (DAT)]. Baraúna, UFERSA, 2010.

trientes do solo. Para folhas, caules e inflorescências, o acúmulo de nitrogênio alcançou valores máximos estimados de $78,33,14,40$, e $6,78 \mathrm{~kg} / \mathrm{ha}$, aos 81,89 e 90 DAT, respectivamente.

Os frutos foram os órgãos com maior acúmulo de nitrogênio, com valor máximo estimado de $133,72 \mathrm{~kg} / \mathrm{ha}$, aos 98 DAT, quando se utilizou o polietileno branco (Figura 2B). Verificou-se que o acúmulo de nitrogênio nos frutos não apresentou diferenças significativas en- tre as coberturas aos 42, 56, 70, 84 e 112 DAT. Aos 98 DAT o polietileno branco e o TNT foram os responsáveis pelo maior acúmulo desse nutriente (Tabela 1). Nos solos sob cobertura plástica, como o polietileno branco, em razão do teor 


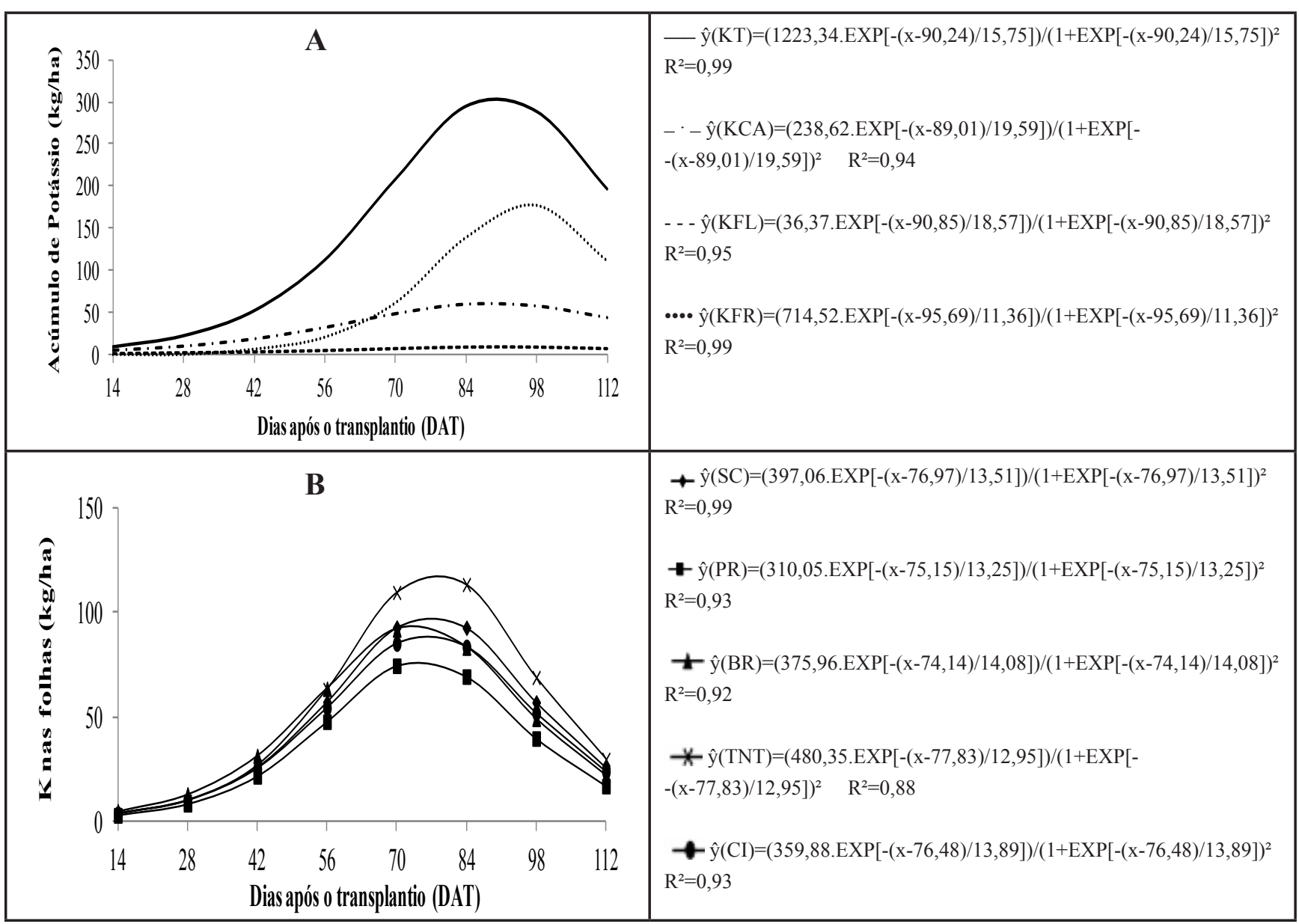

Figura 3. Acúmulo de potássio total (KT), nos caules (KCA), nas inflorescências (KFL), nos frutos (KFR) (A) e nas folhas (KFO) (B) pelo tomateiro 'SM-16' em diferentes coberturas do solo, em função dos dias após o transplantio (DAT) [total potassium accumulation (KT), in stem (KCA), inflorescences (KFL) and fruits (KFR) (A) and leaves (KFO) (B) by tomato 'SM-16' in different mulching depending on days after transplanting (DAT)]. Baraúna, UFERSA, 2010.

mais constante de umidade, uma maior proporção do sistema radicular da planta concentrou-se próximo à superfície do solo, na camada mais rica em matéria orgânica. Nessas condições, a planta explorou o volume de solo com maior disponibilidade de nutrientes, maior retenção de umidade e melhores condições físicas para o crescimento das raízes, aumentando sensivelmente a absorção de elementos essenciais, como o N, pela planta (Sampaio \& Araújo, 2001).

De acordo com Sampaio \& Araújo (2001), o teor de umidade constante e a temperatura mais elevada dos solos com cobertura plástica favorecem a atividade microbiana e a maior mineralização do solo, aumentando a disponibilidade de nitrogênio para as plantas nas camadas mais superficiais do solo, o que pode ter ocorrido nesse caso.

$\mathrm{O}$ fósforo $(\mathrm{P})$, dentre os macronu- trientes estudados, foi o menos absorvido pelo tomateiro, atingindo acúmulo máximo estimado de 24,94 kg/ha, aos 93 DAT. Para folhas, caules, inflorescências e frutos, os valores máximos estimados foram 7,$41 ; 3,521,10$ e $14,83 \mathrm{~kg} / \mathrm{ha}$, aos $83,83,86$ e 98 DAT, respectivamente (Figura 2C). Não foram detectadas diferenças significativas entre as coberturas do solo para o acúmulo desse nutriente.

Os valores de fósforo extraídos do solo pelas plantas são geralmente baixos, principalmente, quando comparados com o nitrogênio e o potássio. Entretanto, os teores desse nutriente bem como a velocidade do seu restabelecimento na solução do solo não são suficientes para atender às necessidades das culturas; como consequência, nas adubações, é o fósforo que entra em maiores proporções (Coutinho et al., 2007).
O potássio $(\mathrm{K})$ foi o nutriente mais absorvido pelo tomateiro, sendo o acúmulo máximo estimado de $305,83 \mathrm{~kg} /$ ha, aos 90 DAT (Figura 3A). Para caules, inflorescências e frutos, os valores máximos estimados foram 59,65; 9,09 e $178,63 \mathrm{~kg} / \mathrm{ha}$, aos 89,91 e $96 \mathrm{DAT}$, respectivamente.

As folhas apresentaram acúmulo máximo de K estimado de $120,09 \mathrm{~kg} /$ ha, aos 78 DAT, quando se utilizou a cobertura do solo com TNT. A maior taxa de absorção ocorreu no período de 42 a 70 DAT. Após atingir o máximo, que variou em função das coberturas do solo, houve decréscimo na quantidade de $\mathrm{K}$ acumulado pelas folhas (Figura 3B). Esse comportamento foi, provavelmente, ocasionado pela grande demanda de $\mathrm{K}$ pelos frutos, fazendo com que ocorresse redistribuição do nutriente para os mesmos. 


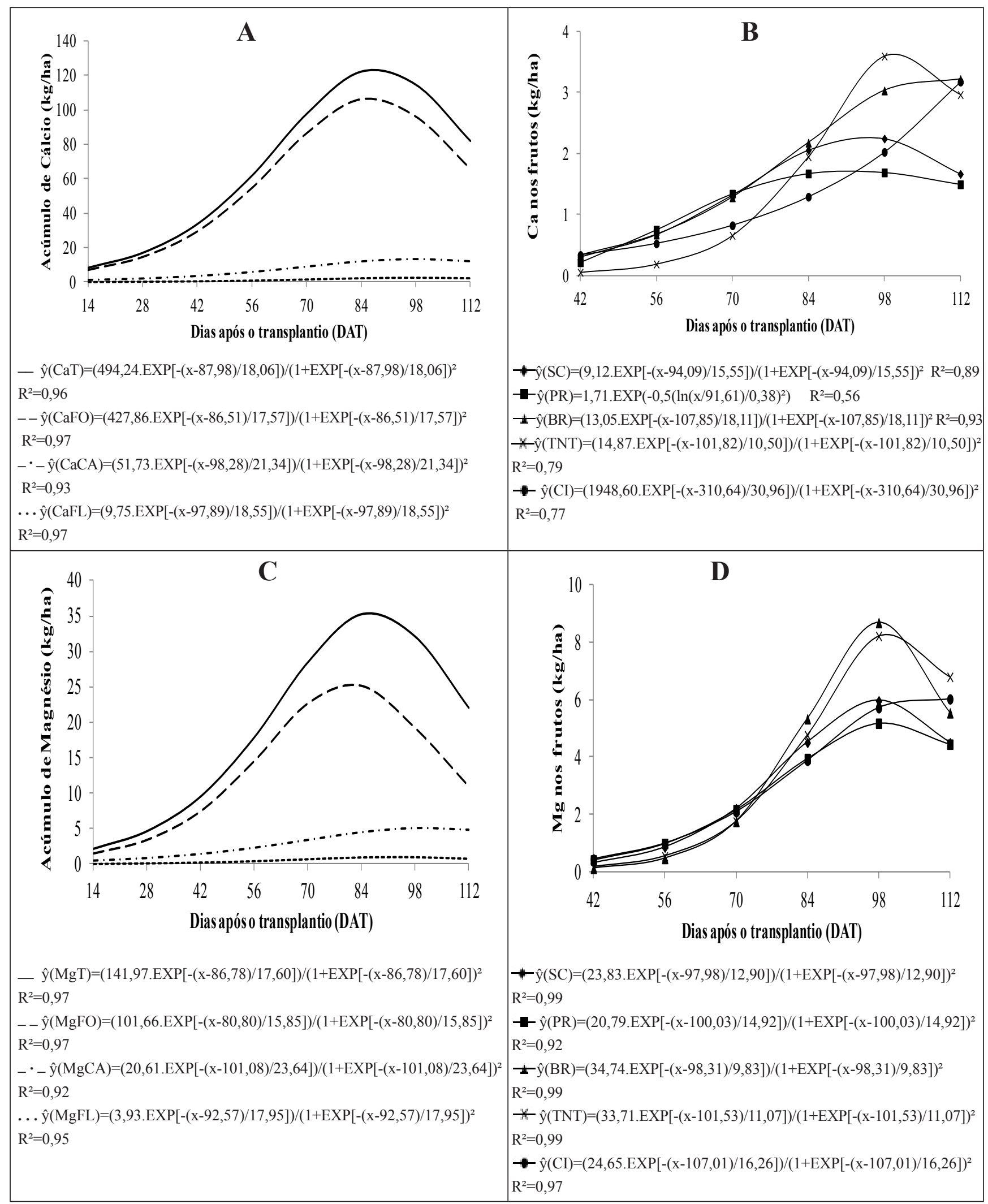

Figura 4. Acúmulo de cálcio total (CaT), nas folhas (CaFO), nos caules (CaCA), nas inflorescências (CaFL) (A) e nos frutos (CaFR) (B), e acúmulo de magnésio total $(\mathrm{MgT})$, nas folhas $(\mathrm{MgFO})$, nos caules $(\mathrm{MgCA})$, nas inflorescências $(\mathrm{MgFL})(\mathrm{C})$ e nos frutos $(\mathrm{MgFR})(\mathrm{D})$ pelo tomateiro 'SM-16' em diferentes coberturas do solo, em função dos dias após o transplantio (DAT) [total calcium accumulation (CaT), in leaves $(\mathrm{CaFO})$, stem $(\mathrm{CaCA})$, inflorescences $(\mathrm{CaFL})(\mathrm{A})$ and fruits $(\mathrm{CaFR})(\mathrm{B})$, and total magnesium accumulation $(\mathrm{MgT})$, in leaves $(\mathrm{MgFO})$, stem (MgCA), inflorescences (MgFL) (C) and fruits (MgFR) (D) by tomato 'SM-16' in different mulching depending on days after transplanting (DAT)]. Baraúna, UFERSA, 2010. 
Não houve diferença entre as coberturas utilizadas aos 14, 28, 42, 70, 98 e 112 DAT para o KFO. Aos 56 DAT o TNT foi responsável, pela maior média, não diferindo estatisticamente do polietileno cinza, do solo descoberto e do polietileno branco, os quais foram superiores ao polietileno preto. Aos 84 DAT, o TNT registrou o maior acúmulo, $134,23 \mathrm{~kg} / \mathrm{ha}$, seguido pelo solo descoberto, polietileno cinza, polietileno branco e polietileno preto (Tabela 2). Acredita-se que o TNT, apesar de ser de cor preta, tenha porosidade que auxilia nas trocas gasosas entre o ar e o solo e, portanto, tende a diminuir a temperatura do solo, quando comparado ao polietileno preto, beneficiando o desenvolvimento das plantas.

Verificou-se, assim como para nitrogênio e fósforo, que os frutos foram os maiores acumuladores de potássio, apresentando aproximadamente $58 \%$ do total absorvido pela planta. À medida que os frutos começaram a se desenvolver, houve incremento na absorção de nitrogênio, fósforo e potássio pelas plantas. As folhas foram, até esse estádio, o órgão da planta com maior concentração desses nutrientes e massa seca. A partir de então passaram gradativamente a se acumular em maior quantidade nos frutos. Segundo Goto et al. (2001), o acúmulo e a distribuição dos nutrientes minerais na planta dependem de seu estádio de desenvolvimento.

$O$ cálcio $(\mathrm{Ca})$ foi o terceiro nutriente mais absorvido pelo tomateiro 'SM-16', com um acúmulo máximo de 123,56 $\mathrm{kg} / \mathrm{ha}$, aos 88 DAT, independentemente das coberturas utilizadas (Figura 4A). Para folhas, caules e inflorescências, os valores máximos estimados foram 106,96, 12,93 e 2,44 kg/ha, aos 86, 98 e 98 DAT, respectivamente.

Os frutos, órgão com menor quantidade de cálcio, apresentaram acúmulo máximo estimado de 3,72 kg/ha, aos 102 DAT, quando se utilizou a cobertura do solo com TNT (Figura 4B). Com relação às coberturas do solo, não foram detectadas diferenças entre os tratamentos aos 42, 56 e 70 DAT. Aos 84 DAT, o maior CaFR foi registrado no tratamento sem cobertura, o qual não diferiu estatisticamente do polietileno branco e do polietileno preto. Aos 98 DAT, o TNT e o polietileno branco registraram os maiores acúmulos, e aos 112 DAT, o polietileno cinza foi responsável pelo maior acúmulo nessa época; no entanto, não diferiu estatisticamente do polietileno branco e do TNT (Tabela 1).

Diferentemente do nitrogênio, fósforo e potássio, o cálcio foi acumulado em maiores quantidades nos órgãos vegetativos do que nos reprodutivos. Comportamento semelhante foi observado por Fayad et al. (2002) e Villas Bôas (2002) em tomate, e por Fontes et al. (2005) em pimentão. O padrão de distribuição do cálcio em favor da parte vegetativa é, portanto, resultado do fato de ele ser transportado quase que exclusivamente pelo xilema e conduzido principalmente pela corrente transpiratória (Grangeiro et al., 2005).

$\mathrm{O}$ acúmulo máximo de magnésio (Mg), quarto nutriente mais absorvido pelo tomateiro 'SM-16', foi 35,49 kg/ ha, aos 87 DAT, independentemente das coberturas estudadas (Figura 4C). Para folhas, caules e inflorescências, os valores máximos estimados foram 25,$41 ; 5,15$ e $0,98 \mathrm{~kg} / \mathrm{ha}$, aos $81,101 \mathrm{e}$ 92 DAT, respectivamente.

Os frutos apresentaram acúmulo máximo estimado de $8,68 \mathrm{~kg} / \mathrm{ha}$, aos 98 DAT, quando se utilizou a cobertura do solo com polietileno branco (Figura 4D). Com relação às coberturas do solo, foi observado que o uso de coberturas não apresentou diferenças estatísticas no acúmulo de magnésio nos frutos aos 42, 56, 70 e 84 DAT. Aos 98 DAT, o polietileno branco foi o que apresentou maior acúmulo, não diferindo do TNT. Aos 112 DAT, destacaram-se o TNT, o polietileno cinza e o polietileno branco (Tabela 1).

O magnésio, embora em menores quantidades que o cálcio, também se acumulou preferencialmente nos órgãos vegetativos, o que pode ser causa de o mesmo fazer parte da molécula de clorofila. Segundo Marschner (2012), dependendo do status de magnésio na planta, entre 6 a $25 \%$ do magnésio total está ligado à molécula de clorofila, outros 5 a 10\% estão firmemente ligados a pectatos, na parede celular, ou como sal solúvel, no vacúolo.

Variações nos fatores ambientais como temperatura e umidade do solo podem ter afetado o conteúdo de nutrientes na planta consideravelmente. Esses fatores influenciaram tanto a disponibilidade dos nutrientes como a absorção deles pelas raízes e, dessa forma, afetaram o crescimento da parte aérea. Portanto, qualquer técnica de cultivo que afete esses fatores, poderá afetar a marcha de absorção de nutrientes na planta ao longo do ciclo. De acordo com os resultados obtidos, constatou-se que as coberturas do solo não influenciaram o acúmulo de massa seca. Os frutos se comportaram como dreno preferencial da planta, chegando ao final do ciclo com $48,6 \%$ do total da massa seca acumulada. Somente acúmulo de N, Ca e $\mathrm{Mg}$ nos frutos e acúmulo de $\mathrm{K}$ nas folhas foram influenciados pelas coberturas do solo. As maiores médias foram obtidas utilizando-se o polietileno branco (NFR: 137,73 kg/ha; MgFR: 8,84 kg/ ha) ou o TNT (CaFR: 4,02 kg/ha; KFO: $134,23 \mathrm{~kg} / \mathrm{ha}) . \mathrm{O}$ acúmulo de nutrientes em ordem decrescente na planta foi: $\mathrm{K}>\mathrm{N}>\mathrm{Ca}>\mathrm{Mg}>\mathrm{P}$, sendo $\mathrm{N}, \mathrm{P}$ e $\mathrm{K}$ encontrados em maiores quantidades nos frutos, e $\mathrm{Ca}$ e $\mathrm{Mg}$ nas folhas.

Considerando-se os resultados alcançados para a produção e seus componentes, percebeu-se que o uso do polietileno branco, não só proporcionou maiores acúmulos de nitrogênio e magnésio nos frutos, como também maior produtividade total, $85,32 \mathrm{t} / \mathrm{ha}$, maior massa média de frutos comerciais, 88,93 $\mathrm{g}$, e maior número de frutos total por planta (119,73 frutos).

\section{AGRADECIMENTOS}

Os autores agradecem ao CNPq, pelo auxílio financeiro à pesquisa; à CAPES, pela concessão de bolsa de mestrado à primeira autora; à WG Fruticultura, pelo apoio logístico e à EMPARN, na pessoa de Tarcisio Dantas, pelo apoio na fase final de laboratório.

\section{REFERÊNCIAS}

ALLEN RG; PEREIRA LS; RAES D; SMITH M. 2006. Evapotranspiración del cultivo: guías para la determinación de los requerimientos de agua de los cultivos. Roma: FAO. 298p. (FAO: Irrigation and Drainage Paper, 56).

ALVARENGA MAR. 2004. Tomate: produção em campo, em casa-de-vegetação e em 
hidroponia. Lavras: UFLA. 400p.

ANTI GR. 2004. Crescimento e acúmulo de nutrientes do tomateiro para processamento industrial. Piracicaba: ESALQ. 52p. (Tese doutorado).

BOGIANI JC; ANTON CS; SELENGUINI A; FARIA JR MJA; SENO S. 2008. Poda apical, densidade de plantas e cobertura plástica do solo na produtividade do tomateiro em cultivo protegido. Bragantia 67: 145-151.

BRAGA JM; DEFELIPO BV. 1974. Determinação espectrofotométrica de fósforo em extratos de solos e plantas. Revista Ceres 21: 73-85.

CÂMARA MJT; NEGREIROS MZ; MEDEIROS JF; BEZERRA NETO F; BARROS JÚNIOR AP. 2007. Produção e qualidade de melão amarelo influenciado por coberturas do solo e lâminas de irrigação no período chuvoso. Ciência Rural 37: 58-63.

COUTINHO ELM; NATALE W; SOUZA ECA. 2007. Adubos e corretivos: aspectos particulares na olericultura. In: GRANGEIRO LC; NEGREIROS MZ; SOUZA BS; AZEVÊDO PE; OLIVEIRA SL; MEDEIROS MA. (Eds). Acúmulo e exportação de nutrientes em beterraba. Ciência e Agrotecnologia 31: 267-273.

EMPRESA BRASILEIRA DE PESQUISA AGROPECUÁRIA. 1999. Centro Nacional de pesquisa do solo. Sistema brasileiro de classificação de solos. Brasília: Serviço de produção de informação. 412p.

EMPRESA BRASILEIRA DE PESQUISA AGROPECUÁRIA. 1999. Manual de análises químicas de solos, plantas e fertilizantes/ Embrapa Solos/Embrapa Informática Agropecuária. In: SILVA, FC (org). Brasília:
Embrapa Comunicação para Transferência de Tecnologia. 370p.

FAYAD JA; FONTES PCR; CARDOSO AA; FINGER LF; FERREIRA FA. 2001. Crescimento e produção do tomateiro cultivado sob condições de campo e de ambiente protegido. Horticultura Brasileira 19: 365-370.

FAYAD JA; FONTES PCR; CARDOSO AA; FINGER FL; FERREIRA FA. 2002. Absorção de nutrientes pelo tomateiro cultivado sob condições de campo e de ambiente protegido. Horticultura Brasileira 20: 90-94.

FELTRIM AL; CECÍLIO FILHO AB; REZENDE BLA; BARBOSA JC. 2008. Crescimento e acúmulo de macronutrientes em chicória coberta e não coberta com polipropileno. Horticultura Brasileira 26: 50-55.

FERREIRA DF. 2007. SISVAR Versão 5.3. Departamento de Ciências Exatas. LavrasMG: UFLA.

FONTES PCR; DIAS EN. GRAÇA RN. 2005. Acúmulo de nutrientes e método para estimar doses de nitrogênio e de potássio na fertirrigação do pimentão. Horticultura Brasileira 23: 275-280.

GARGANTINI H; BLANCO HG. 1963. Marcha de absorção de nutrientes pelo tomateiro. Bragantia 56: 693-713.

GOTO R; GUIMARÃES VF; ECHER MM. 2001. Aspectos fisiológicos e nutricionais no crescimento e desenvolvimento de plantas hortícolas. In: FOLEGATTI MV; CASARINI E; BLANCO FF; BRASIL RPC; RESENDE RS (eds). Fertirrigação: flores, frutas e hortaliças. Agropecuária 2: 241-268.

GRANGEIRO LC; MENDES MAS;
NEGREIROS MZ; SOUZA JO; AZEVÊDO PE. 2005. Acúmulo e exportação de nutrientes pela cultivar de melancia Mickylee. Caatinga 18: 73-81.

HEUVELINK E. 1996. Dry matter partitioning in tomato: validation of a dynamic simulation model. Annals of Botany 77: 71-80.

JANDEL SCIENTIFIC. 1991. Table Curve: curve fitting software. Corte Madera, CA: Jandel Scientific. 280p.

LOPES WAR; NEGREIROS MZ; DOMBROSKI JLD; RODRIGUES GSO; SOARES AM; ARAÚJO AP. 2011. Análise do crescimento de tomate 'SM-16' cultivado sob diferentes coberturas de solo. Horticultura Brasileira 29: 554-561.

MARSCHNER P. 2012. Mineral nutrition of higher plants. San Diego: Academic Press. $651 \mathrm{p}$.

PACE PF; CRALLE HT; EL-HALAWANY SHM; COTHREN JT; SENSEMAN SA. 1999. Drought-induced Changes in Shoot and Root Growth of Young Cotton Plants. The Journal of Cotton Science 3: 183-187.

SAMPAIO RA; ARAÚJO WF. 2001. Importância da cobertura plástica do solo sobre o cultivo de hortaliças. Agropecuária Técnica 22: 1-12.

SENGIK ES. 2010. Os macronutrientes e os micronutrientes das plantas. Disponível em: http://www.dzo.uem.br/disciplinas/Solos/ nutrientes.doc/. Acessado em 27 de novembro de 2010.

VILLAS BÔAS RLV. 2002. Acúmulo de nutrientes em plantas de tomate hibrido Thomas. Relatório Técnico. Syngenta/Rogers. 27p. 